in excellent position, and a great improvement in the action of the muscles." Dr. Althaus reported again as follows : "Nov. 24th, 1897. - Farado-muscular response increased in the sphere of the peroneal nerve, especially tibialis anticus, extensor digitorum, and extensor hallucis longus. No other marked change." Her present condition, Oct. 5th, 1898, is as follows (Fig. 4). The patient is now able to walk about with only a very slight limp and suffers no inconvenience. She wears a light apparatus to take the place of the weak anterior muscles and only requires $\frac{1}{4}$ in. extra thickness on the heel and sole of the left boot. The foot and leg are well nourished and she has never suffered from chilblains or ulcers since the last operation. Dr. Althaus saw her this day and reported that "the leg seems altogether better. Electricaliy less current strength is required to cause muscular action."

It will, of course, require far more experience than that derived from the above cases to enable us to form a fair estimate of what may be expected from division of the tendons of paralysed muscles. It is obvious that such a procedure cannot be expected to restore action in muscles which have become absolutely degenerated, nor can we expect paralysed nerves to be capable of regaining their function. It seems certain, however, that the significance of what is called the "reaction of degeneration" must be modified, for it would appear that this symptom does not prove that no power of recovery exists. The results in the two,cases recorded above are so definite that I cannot see any other explanation of the benefits derived than that suggested. The advantages are obvious and great. In the first case it means the difference between the child being absolutely cured in a few months and having to wear some mechanical support for the rest of her life. In the second case, although some weakness remains, yet the improvement is very considerable, and I would further point out that this improvement is distinctly more than could be expected as the result only of making the joint more free. I could record other cases in which apparently similar results have been obtained, but as no electrical examination was made before operation I prefer to limit my report to the above two instances.

Queen Anne-street, w.

\section{Clinital Altes:}

\section{MEDICAL, SURGICAL, OBSTETRICAL, AND THERAPEUTICAL.}

\section{A RARE, IF NOT UNIQUE, FRACTURE OF THE TIBIA.}

By LeONaRd Molloy, M.A., M.D. Dub.,

HOYORARY SURGEON TO THE VICTORIA HOSPITAL, BLACKPOOL.

THE patient was a man, aged sixty-five years. On Hay 19th, 1897, while getting into his cart with his right foot on the step his pony started. He endeavoured by hopping along on his left foot to keep pace with the pony and so clamber into the vehicle, but while so doing he fell away from the trap on to his left side. He felt that he had sustained an injury to his left knee and found that he could not stand. He was removed to hospital where he came under my care. The knee-joint was enormously swollen and it was exceedingly difficult to localise the injury, but I came to the conclusion that there was an almost vertical fracture through the head of the tibia, opening, of course, into the joint, and that the greater part of the external tuberosity, with the fibula attached to it, was separated from the head of the bone. There was no fracture of the fibula. The difficulty of diagnosis was increased by the fact that there was shortening of the affected limb to the extent of $1 \frac{1}{2} \mathrm{in}$., but this I was enabled to satisfy myself was due to a fracture of the left femur which the patient had sustained in childhood and for which he had beeu treated in Genoa. The limb was put up on a Lawrence's back splint and so treated throughout. An attempt was made to take a radiogram of the injury before the effusion into the joint had subsided, but it was unsuccessful. Later, however, a radiogran was taken by Mr. T. D. Whittington of this town, of which a reduced reproduction of the photographic print is annexed. The photographic plate was placed behind the knee. From measurements made on the original radiogram it appears that the fracture ran from a point on the articular surface of the head of the bone, $2 \frac{1}{2}$ in. from the internal border of the internal tuberosity, almost directly downwards for 2 in., when it came flush with the shaft of the bone and so separated the major portion of the external tuberosity. This fragment could be moved antero-posteriorly, when the resulting crepitus gave one the idea of two broad surfaces rubbing one upon the other. I am quite sure that there was



Radiogram showing deformity of head of tibia resulting from fracture.

no other line of fracture in the head of the bone. Heyden. reich's plate of an injury to the "head of the tibia with division of the superior extremity into many pieces" shows a $\boldsymbol{W}$-shaped line of fracture, one of the limbs of which takes exactly the line which, I believe, was present in the above case, the cause being, as in this, concussion of the tibial head by the femoral condyles. I am unable to find a record of a similar case to the above. The patient is now able to walk as well as he did before the accident. On measurement with callipers I found that there was broadening of the head of the tibia from side to side to the extent of $\frac{3}{4}$ in.

Blackpool, Lanes.

\section{SUCKLING A CAUSE OF ABORTION.}

By 'T. M. Callender, M.B., C.M. Edix., LATE RESIJENT SURGEON ROYAL MATERNITY AYD SIMPSON MEMORIAT HOSPITAL, EDIXBURGH.

I THINK the following case of abortion of interest on account of the cause which I attributed it to-viz., suckling.

The patient, a woman, aged about thirty years, who had had five children, was well-developed, strong, and healthy, with nothing abnormal in her previous menstrual history. There was no history of endometritis or of specific illness. Her first child was born seven years ago and her last twelve months ago. All her labours were normal except the last but one, when the child was stillborn. It was a breech presentation and there had been some ante-partum hæmorrhage two months before birth. There were no previous iniscarriages. Since the last child was born she had one menstrual period, three months ago; she missed the next period and at the date when she should have had her third period she began to suffer from uterine pains and hæmorrhage. She had suffered from morning sickness during the last month. Her breasts were large and full of milk, which was watery in 